\title{
Micro-CT and Wettability Analysis of Oil Recovery from Sand Packs and the Effect of Waterflood Salinity and Kaolinite
}

\author{
Evgenia V. Lebedeva and Andrew Fogden* \\ Department of Applied Mathematics, Research School of Physics and Engineering, Australian National University, Canberra ACT 0200, \\ Australia
}

Supporting Information

ABSTRACT: An image-based approach was developed by combining microtomography with electron microscopy and contact angle goniometry to determine the pore-scale distribution of crude oil in plugs after waterflooding and shed light on the molecularscale mechanisms responsible. The approach was applied to a model rock comprising a pack of quartz sand grains without or with a preapplied lining of kaolinite, imaged prior to and after capillary-driven oil recovery by flooding with a model brine of high or low salinity. The presence of kaolinite increased residual oil and reversed its brine dependence, with high-salinity flooding giving greatest recovery from the clean sand and least recovery from kaolinite-coated sand. These two extremes tended to exhibit the most connected residual oil clusters, while low salinity gave smaller blobs, to the detriment or advantage of oil recovery. Low-salinity flooding in secondary or tertiary recovery mode resulted in comparable oil residuals in kaolinite-coated sand. Surface analysis of the grains and model substrate analogs without or with this coating showed that recovery was correlated to the advancing contact angle. In particular, kaolinite was far more resistant than quartz to wettability alteration by this particular crude oil, resulting in a more water-wet state prone to oil trapping via bypassing and snap-off mechanisms.

\section{INTRODUCTION}

Improved or enhanced oil recovery demands the continued development of viable waterflooding strategies to reduce residual oil during secondary recovery or recover this residual in tertiary mode. More systematic and predictive approaches to optimization require further advances in our current foundational knowledge of the microscopic capillarity subprocesses of oil displacement and trapping.

A substantial body of research into waterflooding and residual oil at the pore scale has been performed on porous media such as bead and grain packs and $2 \mathrm{D}$ etched glass micromodels. ${ }^{1-3}$ The vast majority of these results pertain to media of uniform, fixed wettability, usually water-wet. On primary drainage of water by injected oil, the irreducible water occupies the smaller pores and sheathes pore walls. On subsequent imbibition of water to displace oil, capillary oil trapping can occur via bypassing and/ or snap-off. The former is mainly dictated by the pore size distribution, with rapid spontaneous advance of water through smaller pore subnetworks bypassing connected oil in larger pore clusters. Snap-off is instead determined by the aspect ratio of pore body width to connecting pore throat width, with oil rupture in tight bridging throats leading to discrete residual blobs in bodies. ${ }^{1-3}$ If the ratio of viscous forces (capillary number) or gravitational forces (Bond number) to capillary forces exceeds a threshold, entrapment decreases and mobilization of residuals becomes possible. Mobilization onset correlates to capillary numbers $\sim 10^{-5}$ in water-wet sandstones, ${ }^{4,5}$ or $10^{-3}$ in unconsolidated water-wet bead packs. ${ }^{3}$

Over the past decades, awareness has grown that most reservoirs are not water-wet. Crude oil can alter this pristine rock state by adsorbing or depositing polar components, namely its asphaltenes and resins. This is often thought to result in a mixed-wet state of relatively oil-wet pore wall subareas over which oil contacts and adheres, intermingled with unaltered subareas covered by the connate brine. ${ }^{6-9}$ Studies of model substrate analogs ${ }^{10-14}$ have facilitated characterization of local wettability alteration by macroscopic contact angle and atomic force microscopy of micro/nanoscopic deposit morphology to shed light on the oil-brine-mineral interactions responsible.

The insights from displacement in uniformly wet porous media and wettability alteration of smooth substrates were combined into pore-scale numerical models of mixed-wet networks. ${ }^{15-17}$ The recent advances in X-ray computed microtomography ( $\mu$-CT) have made possible the 3D pore-scale imaging of model and reservoir rock plugs, ${ }^{18-20}$ providing more realistic pore spaces for modeling. Progress has also been made in $\mu$-CT imaging of immiscible fluid phases in rock pores, via the addition of X-ray attenuating contrast agents. ${ }^{21,22}$ Imaging to date has focused on simple fluids and idealized wettability states. More realistic scenarios in which the aqueous phase is drained by crude oil and aged, followed by waterflooding and pore-scale analysis of residual crude, remain largely unexplored.

A body of recent experimental work has furthered understanding of wettability at the pore scale and below, principally by imaging asphaltenic deposits with field emission scanning electron microscopy (FESEM). The wettability state after crude oil drainage of the initial brine and aging was imaged in glass bead packs, ${ }^{23}$ giving extra credence to the presumption of mixed wettability. Reservoir sandstones are obviously far more complex than bead packs, and often contain a variety of clays

\footnotetext{
Received: August 16, 2011

Revised: October 29, 2011

Published: November 14, 2011
} 


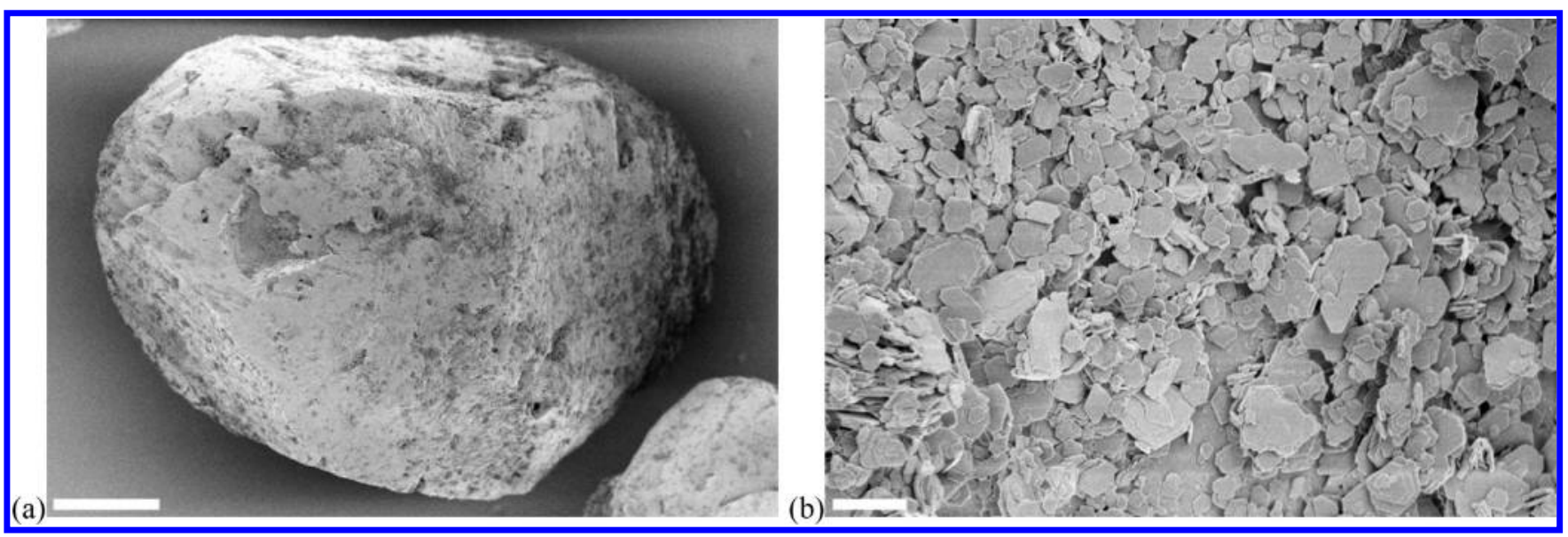

Figure 1. FESEM images of a (a) sand grain coated with kaolinite (scale bar $100 \mu \mathrm{m}$ ) and (b) close-up within a grain subarea well covered by kaolinite (scale bar $1 \mu \mathrm{m}$ ).

(with kaolinite the most prevalent) distributed in a variety of ways (filling, spanning, and/or lining pores). The clays can variably increase or decrease overall oil-wetness, depending on their associated impacts on absolute permeability and initial saturations. ${ }^{9,24}$ To isolate their inherent capability to alter wettability, the vocabulary of model substrates was extended by smoothly coating kaolinite particles on glass to image the brinedependent deposition of asphaltenics on platelet faces and edges and relate these to oil drop contact angles. ${ }^{25,26}$ The FESEM technique was further applied to image deposits in sandstones and mobilization of their kaolinite particles during flooding. ${ }^{27}$ Analysis of model substrates also demonstrated that the wettability state typically evolves during flooding. ${ }^{28}$

The current study unifies these recent advances, by $\mu$-CT imaging the pore-scale distribution of residual crude oil in plugs after drainage, aging, and flooding, and combining this with FESEM and contact angle analyses of the wettability of analog substrates and pore walls. It proves convenient to use plugs of unconsolidated quartz sand packs, rather than consolidated sandstones. This allows the freedom to increase pore size to improve $\mu$-CT resolution, and to preapply a controlled distribution of kaolinite linings on the grains before pack assembly to test their effect on recovery and wettability. The influence of the flood salinity, including the effect of the added contrasting salt, is also addressed.

\section{EXPERIMENTAL SECTION}

Materials. The porous media used were sand packs, without or with kaolinite on grain surfaces, confined between glass frits. The quartz sand (F-30; Ottawa, IL; U.S. Silica) is composed of $99.8 \%$ silica as unground round grains, with $22.3 \%$ retained by sieve mesh $30(600 \mu \mathrm{m})$ and cumulatively $92.5 \%$ by mesh 40 $(425 \mu \mathrm{m})$. The kaolinite (KGa-1b; Washington County, GA; Clay Minerals Society) is composed of $96 \%$ kaolinite and has cation exchange capacity $3.0 \mathrm{meq} / 100 \mathrm{~g}$ and surface area 11.7 $\mathrm{m}^{2} / \mathrm{g}$. ${ }^{29-31}$ The frits (Robuglas) were 3-mm thick with pore size 250-500 $\mu \mathrm{m}$. Sand and frits were cleaned with toluene, 50/50 $(\mathrm{v} / \mathrm{v})$ toluene/methanol, methanol, and deionized water from a Millipore Milli-Q system (as used throughout). They were further cleaned by radio frequency water-vapor plasma (at 50 $\mathrm{W}$ for $1 \mathrm{~min}$ ) directly prior to kaolinite coating of grains or assembly of the pack. Kaolinite was not cleaned from its received state. Supporting experiments on model substrates used rectangular pieces $(7 \mathrm{~mm} \times 26 \mathrm{~mm})$ of microscope glass slide (Knittel Gläser), precleaned as above, without or with a $\sim 0.5 \mu \mathrm{m}$ thick kaolinite coat applied via a published method. ${ }^{25,26}$

The crude oil was from the Tensleep formation, Wyoming, with density $0.8682 \mathrm{gcm}^{-3}$ at $20{ }^{\circ} \mathrm{C}$, viscosity $14.3 \mathrm{mPa} \cdot \mathrm{s}$ at $25{ }^{\circ} \mathrm{C}, \mathrm{n}-\mathrm{C}_{7}$ asphaltene content 3.2 wt $\%$, and acid and base numbers 0.16 and $0.96 \mathrm{mg} \mathrm{KOH} / \mathrm{g}^{14}$ Sand pack experiments used two aqueous salt solutions: $0.075 \mathrm{M}$ CsI (cesium iodide; Sigma Aldrich) and a $0.75 \mathrm{M}$ mix of $0.125 \mathrm{M}$ CsI and $0.625 \mathrm{M}$ $\mathrm{NaCl}$ (AnalaR). The CsI enhances the attenuation difference between aqueous phase and crude oil in $\mu$-CT imaging, ${ }^{22}$ with $0.075 \mathrm{M}$ being close to the minimum required to contrast the two liquids. Model substrate experiments used these two solutions plus pure $\mathrm{NaCl}$ solutions of these two total concentrations. All solutions were used at their natural, unadjusted $\mathrm{pH}(5.8 \pm 0.2)$.

Sand Pack Preparation and Flow Experiments. Kaolinitecoated sand was prepared by filtering $8 \mathrm{~g}$ of 1 wt \% kaolinite suspension through a 7 -g bed of sand, which was then dried at $60{ }^{\circ} \mathrm{C}$ for $2 \mathrm{~h}$. The sand was flushed with $0.75 \mathrm{M} \mathrm{NaCl}$ to strip very loosely bound kaolinite, and similarly dried. The average kaolinite coat weight was 0.28 wt \% relative to sand. FESEM (Zeiss UltraPlus Analytical) images show that the coat is patchy, corresponding to the darker subareas in Figure 1a. Kaolinite is strewn as isolated particles, monolayers, and multilayers, with platelets generally parallel to the surface, together with disoriented aggregates and pre-existing booklets (Figure $1 \mathrm{~b}$ ).

The cylindrical sample holder of the $\mu$-CT mountable flow cell had outer and inner diameter of 10 and $8 \mathrm{~mm}$ and length $27 \mathrm{~mm}$, with transparent plastic walls. It was packed with $\sim 1.8 \mathrm{~g}$ of sand (without or with kaolinite precoating) to a height of $21 \mathrm{~mm}$ between the $8 \mathrm{~mm}$ diameter frits at top and bottom. The column was compacted by tapping and the ends of the holder were screwed tight. The $0.75 \mathrm{M} \mathrm{CsI} / \mathrm{NaCl}$ solution was injected at $57 \mathrm{~cm}^{3} / \mathrm{h}$ using a syringe pump to saturate the pack. The cell was then dismantled and the holder was contacted with filter paper in a sealed vessel at $100 \%$ humidity to drain the salt solution from the sand and frits without evaporation. Drainage was continued until $\sim 10$ wt $\%$ of the original solution remained. The holder was reconnected to the cell and pump to inject 30 pore volumes (PV, with $1 \mathrm{PV} \approx 0.35 \mathrm{~cm}^{3}$ ) of crude oil in one direction through the sample at $57 \mathrm{~cm}^{3} / \mathrm{h}$ (which corresponds to capillary number $\mathrm{Ca}=2 \times 10^{-4}$, assuming an oil interfacial tension of $\sim 30 \mathrm{mN} / \mathrm{m}$ 


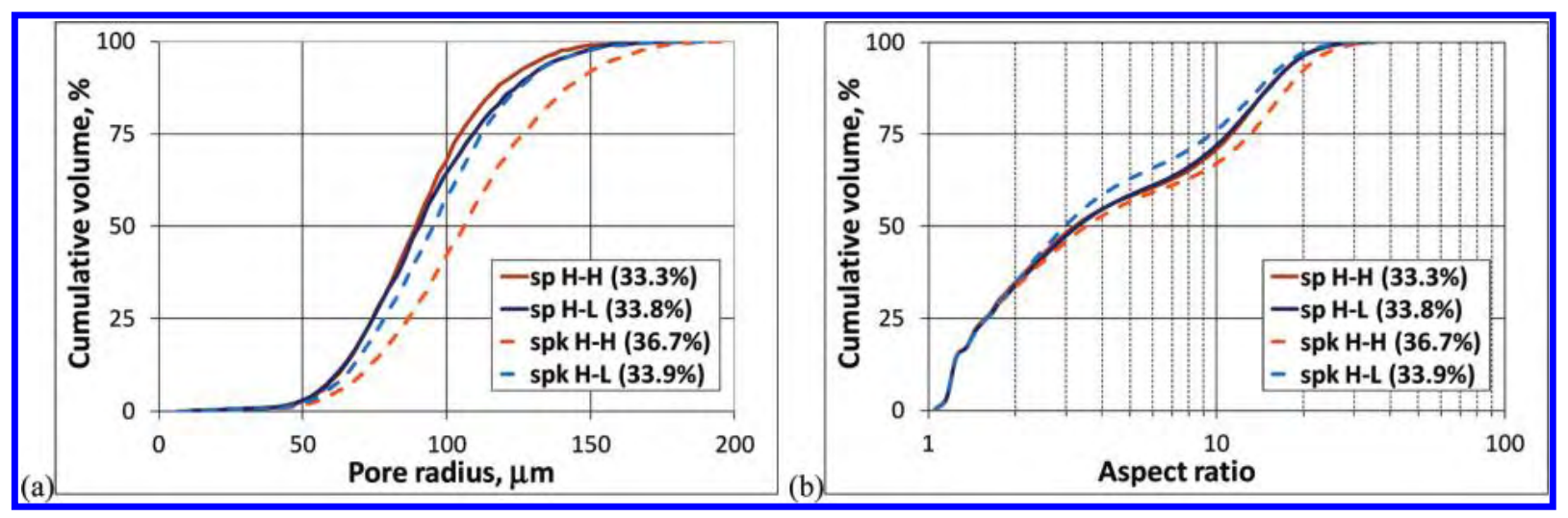

Figure 2. Volume-weighted distributions of pore (a) inscribed radius and (b) aspect ratio, from the segmented tomograms of the four samples after aging, with overall porosity in the legend.

against either air or salt solution) to displace the air. The cell was sealed and aged for 7 days at $60^{\circ} \mathrm{C}$, followed by $\mu$-CT scanning (see below) of this oil-drained state. It was then waterflooded by injecting $25 \mathrm{PV}$ of the high-salinity $(0.75 \mathrm{M} \mathrm{CsI} / \mathrm{NaCl})$ or low-salinity $(0.075$ $\mathrm{M}$ CsI $)$ solution in this same direction at $2.0 \mathrm{~cm}^{3} / \mathrm{h}(\mathrm{Ca}=4 \times$ $10^{-7}$ ) for $3 \mathrm{~h}$, while held at $60^{\circ} \mathrm{C}$. This "secondary" recovered state was then $\mu$-CT scanned. For the kaolinite-coated sand, high-salinity flooding was followed by low-salinity flooding and a third scan of this "tertiary" recovered state. The wettability of the kaolinite-coated sand after flooding was analyzed as outlined below.

$\boldsymbol{\mu}$-CT Scanning. Tomograms were obtained and analyzed using the ANU $\mu$-CT facility. ${ }^{18}$ After each of the above steps, the sealed flow cell was mounted in the $\mu$-CT rotatable stage. The X-ray source was set to $80 \mathrm{kV}$ and $100 \mathrm{~mA}$, with filtered Bremsstrahlung used to acquire 2880 projections of $2048^{2}$ pixels over $20 \mathrm{~h}$. The projection set covered a 10.4-mm cube surrounding the center of the sample, thus scanning its middle half to minimize the influence of any end effects. The projections were reconstructed to a $3 \mathrm{D}$ raw tomogram, with voxel size $5.5 \mu \mathrm{m}$. Tomograms were processed with Mango software, including anisotropic diffusion filtering, cropping of external walls, alignment and segmentation of the mineral, aqueous, and oil phases. ${ }^{19,20}$

Analysis of Model Systems. Zeta potential of crude oil (emulsified), quartz (finely ground F-30 sand), and kaolinite was measured in the four salt solutions using a Zetasizer Nano-ZS (Malvern Instruments). ${ }^{25}$ The ability of kaolinite particles to interfacially stabilize crude oil drops in the solution was assessed by shaking and counting the macro-emulsion drops remaining 6 min later, using a published procedure. ${ }^{27}$ The tendency for sand, without or with lining kaolinite, to alter its water-wet state toward oil-wetness during short-term crude oil exposure was tested by oil pendant drop experiments on the glass slide, without or with its kaolinite coat, in the solution. Receding and advancing contact angles on drop growth and retraction were measured through the aqueous phase by a goniometer (KSV Instruments) using a protocol detailed elsewhere. ${ }^{25}$

Longer-term wettability alteration was tested using established procedures. ${ }^{26,28}$ The model substrate was pre-equilibrated in the solution in a vial with crude oil above, after which the solution was withdrawn by pipet. Further drainage of the aqueous film enveloping the oil-immersed substrate was performed by centrifuging the vial at $1000 \mathrm{~g}$ for $10 \mathrm{~min}$. This was followed by aging for 7 days at $60^{\circ} \mathrm{C}$, as in the sand pack experiments. Bulk oil was removed with decalin and the salt was removed with methanol, to leave the adsorbed/deposited asphaltenics. This adhering material was imaged by FESEM. It was also extracted from the kaolinite-coated glass using an azeotropic chloroform/methanol blend to determine its dissolved mass using a FluoroMax-3 spectrofluorometer (Horiba Jobin Yvon). ${ }^{26}$ The emission intensity at $496 \mathrm{~nm}$ from $340 \mathrm{~nm}$ excitation was calibrated to concentration via the same analysis of prepared solutions of Tensleep asphaltenes (see Supporting Information).

These latter two techniques were also applied to the kaolinitecoated sand after flooding and $\mu$-CT. The holder contents were transferred to a tube with the corresponding salt solution and centrifuged at $1000 \mathrm{~g}$ for $10 \mathrm{~min}$ to remove oil, and then methanol immersed and ambiently dried. Some grains with kaolinite were inspected by FESEM; the remainder was solvent extracted for fluorescence spectroscopy.

\section{RESULTS AND DISCUSSION}

$\boldsymbol{\mu}$-CT Characterization of Pore Space and Drained State. The $\mu$-CT sample matrix comprised two sand packs without kaolinite (denoted $s p$ ) and two with kaolinite coating (denoted $s p k$ ), each of which was initially saturated with high-salinity solution $(0.75 \mathrm{M} \mathrm{CsI} / \mathrm{NaCl}$, denoted $H)$, drained by oil and aged, and then flooded with this same solution or its low-salinity counterpart (0.075 M CsI, denoted $L)$. Samples are thus referred to as $s p H-H$, sp $H-L$, spk $H-H$, and spk $H-L$. The tomograms distinguished the $3 \mathrm{D}$ locations of grains (the most strongly attenuating phase, appearing very light gray), and aqueous (intermediate, hence darker gray), and oil (weakest, hence darkest) phases occupying the pore space, readily facilitating their segmentation. The 0.2-mm annulus closest to the holder wall was excluded from analysis. The pore space was topologically partitioned into pore bodies and throats. ${ }^{19}$ The following analysis pertains to the four tomograms after aging (prior to flooding).

For all samples the grain packs appeared homogeneous and similar. Statistics of the inscribed radii of all pores and their body/ throat aspect ratio are presented in Figure 2. Porosity and pore size vary only slightly between samples in Figure $2 \mathrm{a}$, with the dominant contribution to volume coming from intergrain pore radii tightly distributed between 50 and $150 \mu \mathrm{m}$, with median in the range $89-106 \mu \mathrm{m}$. The direct effect of the thin kaolinite lining (Figure 1) on structural properties and absolute permeability of the coarse sand packs is expected to be minimal, thus the tendency for coated grains to give slightly larger porosity and 


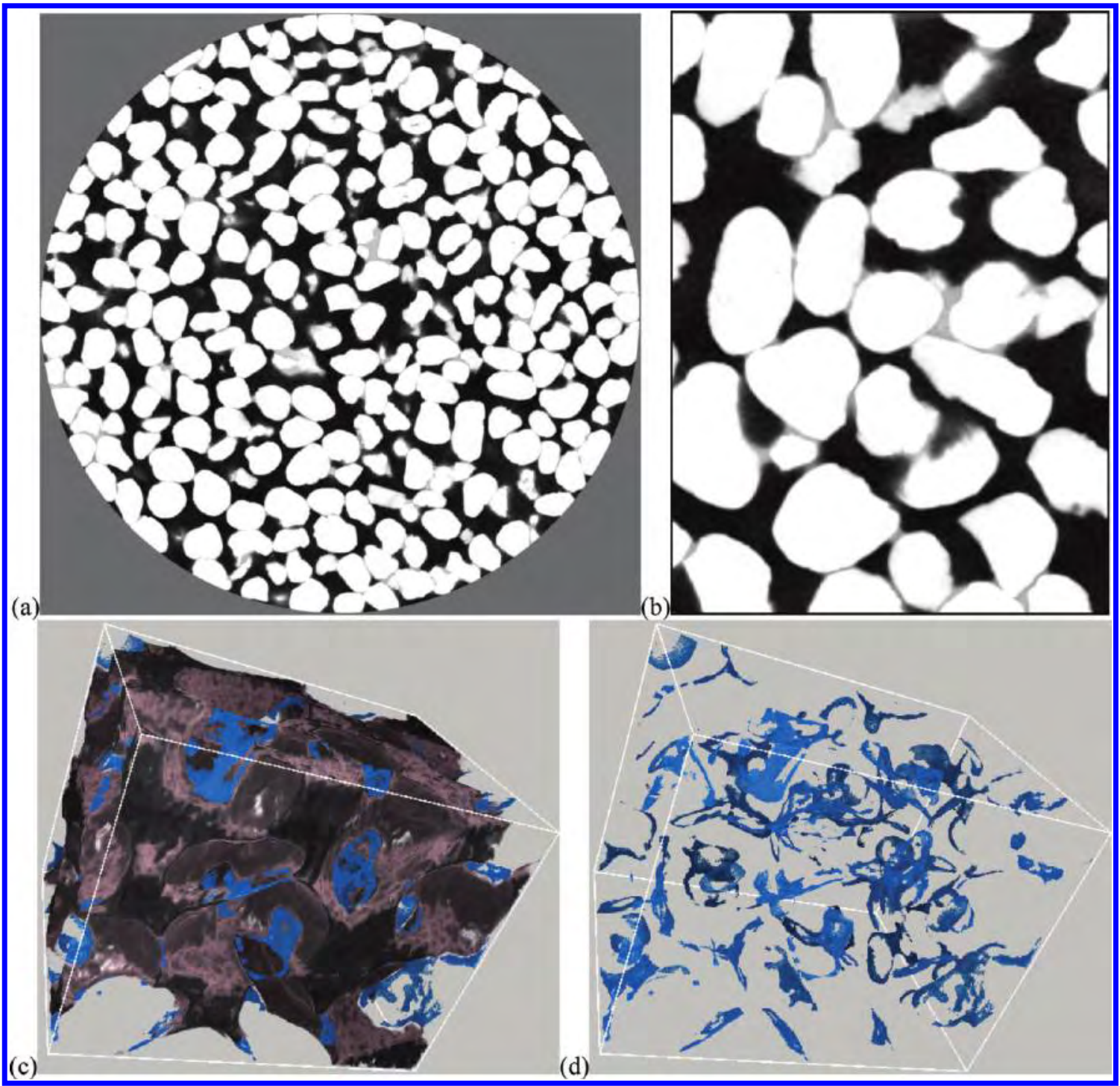

Figure 3. $\mu$-CT images of kaolinite-coated sand packs after oil drainage of salt solution and aging: (a) $2 \mathrm{D}$ horizontal slice of the $8 \mathrm{~mm}$ diameter of spk $H-H$, (b) subarea $(2.0 \mathrm{~mm} \times 2.7 \mathrm{~mm})$ of this slice, (c) $3 \mathrm{D}$ visualization of a subvolume $(1.7 \mathrm{~mm} \times 1.3 \mathrm{~mm} \times 1.3 \mathrm{~mm})$ of spk H-L showing crude oil (black) and salt solution (blue) without grains, and (d) showing only the solution.

pore size may be due to greater friction during compaction. For each throat in the network, the aspect ratio in Figure $2 b$ is the ratio of the arithmetic mean radius of the two pores it connects to the throat radius, weighted by volume of the two pores. It also varies little between samples, with median from 3.0 to 3.5. The pore spaces are thus structurally very similar, highly permeable, and well connected.

Representative images of $s p k H-H$ and $s p k H-L$ after aging are given in Figure 3. As expected, the salt solution has been drained to remain only in the tighter confines, filling smaller pores or occupying the corners of larger pores, often in the form of rings collaring grain contacts. These pendular rings are more apparent in the visualizations of Figure $3 \mathrm{c}$ and $\mathrm{d}$ using Drishti software. Some rings are connected to neighbors, while others appear isolated and/or incomplete, however hydraulic connectivity may persist in grain roughness and lining kaolinite, below $\mu$-CT resolution. All samples appear qualitatively as in Figure 3. Moreover, their irreducible water saturation, $S_{\text {wi }}$, resolved in the pore space of the segmented tomograms for this initial state is very similar $(9.9,11.2,10.1$, and $8.6 \%$ for $s p H-H$, sp $H-L$, spk $H-H$, and $s p k H-L$, respectively). These values tally with the gravimetric estimate at the conclusion of air drainage, and are in line with other studies of granular packs. ${ }^{1,32}$ The kaolinite linings do not lead to bulk water drainage from small pores, as was inferred from a $\mu$-CT study of water-wet Berea sandstone. ${ }^{21}$

$\boldsymbol{\mu}$-CT Pore-Scale Characterization of Residual Oil. Owing to the small sample size required for $\mu$-CT, oil production was not monitored volumetrically during flooding. Instead, the residual oil saturation, $S_{\text {or }}$ after the 25 PV flood was determined from the segmented tomograms. Figure 4 plots the percentage of pore space occupied by oil voxels postflooding relative to the initialstate percentage $\left(100-S_{\mathrm{wi}}\right)$ of original oil in place (OOIP), for the four once-flooded samples and the one subsequent lowsalinity flooding (spk $H-H-L)$ in "tertiary" mode. The most striking feature is the detrimental effect of the small amount of kaolinite, which on average more than doubles $S_{\text {or. }}$ The kaolinitefree sand pack flooded at high salinity $(s p H-H)$ gave the most complete recovery, with its low-salinity counterpart sp H-L 
leaving 5\% OOIP more residual. Kaolinite reverses this trend, with low-salinity flooding $(s p k H-L)$ producing more oil than high-salinity $(s p k H-H)$. The disadvantageous effect of kaolinite is thus most pronounced for high-salinity flooding. Subsequent low-salinity flooding ( $s p k H-H-L)$ reduced the residual to a level comparable to "secondary" recovery (spk $H-L)$.

Understanding of the mechanisms responsible entails investigation of oil residuals at pore-scale (in the remainder of this subsection) and down to molecular scales (the following subsection). Typical slices within the segmented tomograms of the four packs after secondary recovery (single flooding) are compared in Figure 5. Although sp $\mathrm{H}-\mathrm{H}$ has lowest $S_{\text {or }}$, the residual oil blobs appear to link many pores (even in the 2D slice which under-represents $3 \mathrm{D}$ connections), tending to snake along somewhat tighter macropores. Although $s p H-L$ has more residual, it appears less connected in Figure 5, and often occupies

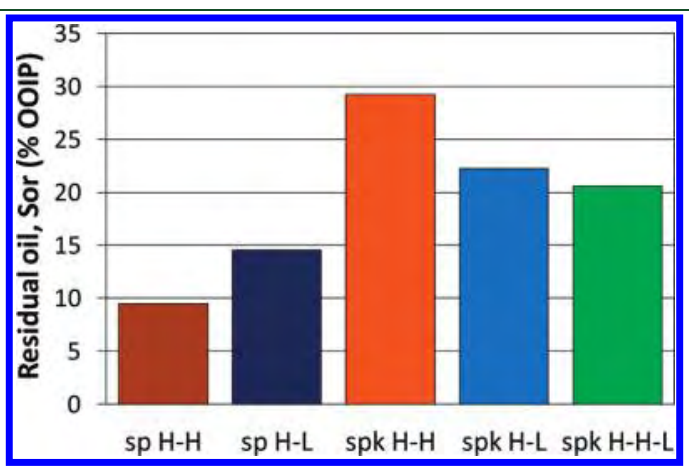

Figure 4. Residual oil fractions resolved from $\mu$-CT of sand packs without $(s p)$ or with $(s p k)$ kaolinite linings, after flooding at high $(-H)$ or low $(-L)$ salinity, or both sequentially $(-H-L)$ for the final sample. somewhat larger pores. Sample $s p k H-H$ has greatest residual, in the form of highly connected clusters often filling somewhat larger pores, while the lower residual for spk $H-L$ exhibits less pore linkage.

Tomograms after aging and after flooding(s) were aligned and superposed using a registration algorithm. ${ }^{20}$ Comparison of these registered images showed no significant grain movement during flooding. The differences in recovery are thus due to kaolinite and the flood salinity. Figures 6 and 7 show registered 2D slices and $3 \mathrm{D}$ visualizations of the coated grain pack after aging and the $H$ flood (spk $H-H)$ and following $L$-flood (spk $H-H-L)$. From the drained and aged state in Figure 6, the flooding aqueous phase largely maintains its initial occupation of tighter pore confines (as seen in other studies ${ }^{22}$ ) while advancing to displace oil, leaving residuals ranging from isolated blobs in single pores (singlets) to connected clusters spanning many pores. From the secondary recovered state, the pore-scale changes in residual on tertiary recovery in Figures 6 and 7 are identifiable as resulting from further advance of aqueous phase causing further oil retraction. Smaller blobs isolated after secondary recovery typically remain unperturbed. Oil in larger clusters recedes, leading to complete displacement from some pores, thinning in other pores, and frequent incidences of snap-off in tighter pores and throats, together serving to reduce the residual and its blob connectivity. As all floods were performed at the same low capillary number $\left(4 \times 10^{-7}\right)$ and Bond number $\left(\sim 3 \times 10^{-3}\right)$, the extra recovery cannot be due to blob mobilization. ${ }^{3}$

Figures 5-7 demonstrate that the vast majority of pores retaining trapped oil are only partially filled by it. The distributions of pore occupancies are quantified below. Whereas the variations are due to the variable pore geometry and topology, they may also reflect the additional contribution of contact angle

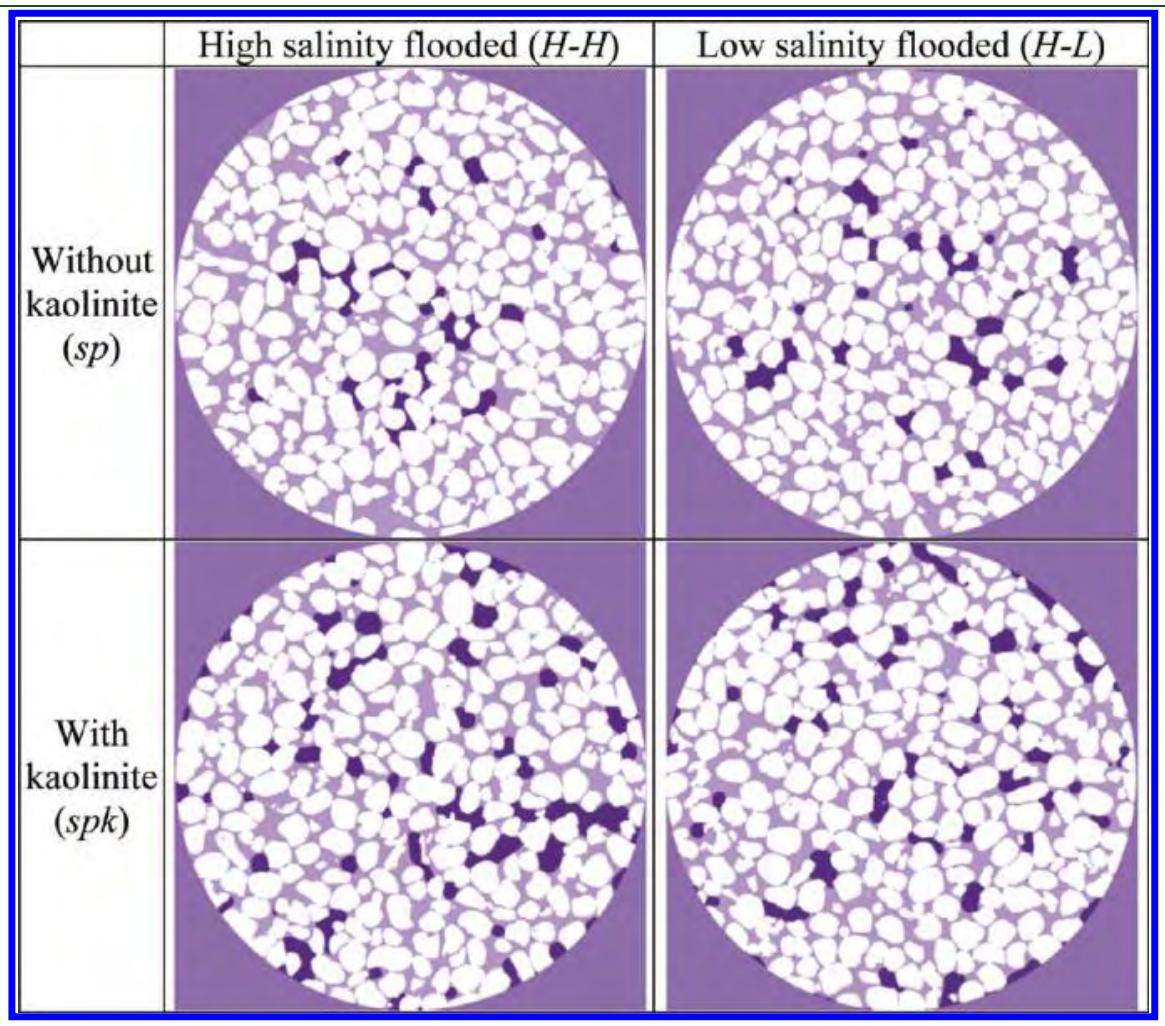

Figure 5. 2D horizontal slices of the segmented tomograms for the 8-mm diameter sand packs without or with kaolinite after high- or low-salinity flooding. Grains are white, salt solution is light purple, and oil is darkest purple. 


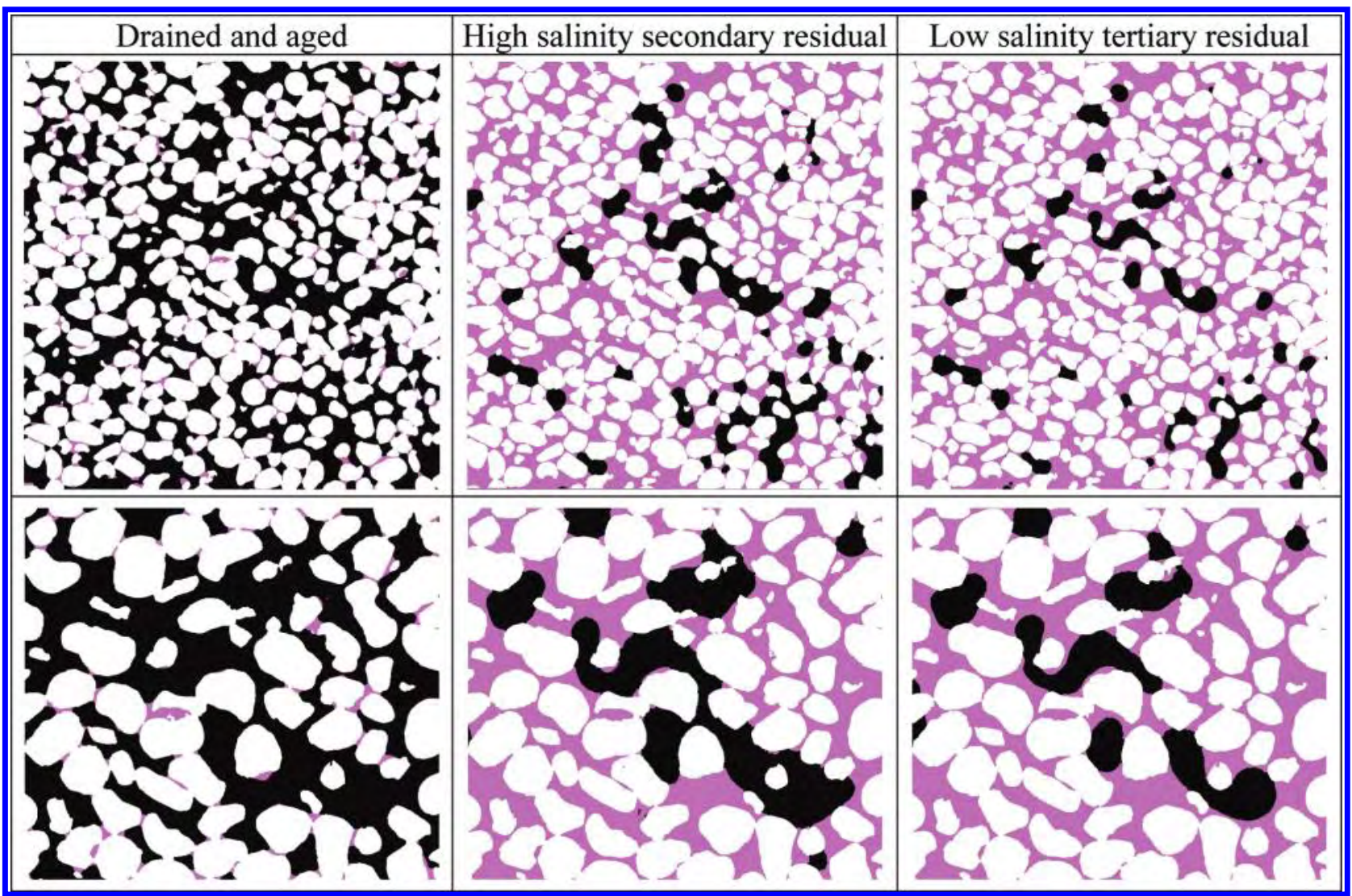

Figure 6. Corresponding vertical slice (after flow in the upward direction) of the registered segmented tomograms of $s p k H$ - $H-L$ in its three imaged states, showing a subarea $(7.4 \mathrm{~mm} \times 7.6 \mathrm{~mm}$, above $)$ and a close-up $(3.7 \mathrm{~mm} \times 3.3 \mathrm{~mm}$, below $)$ near its center.

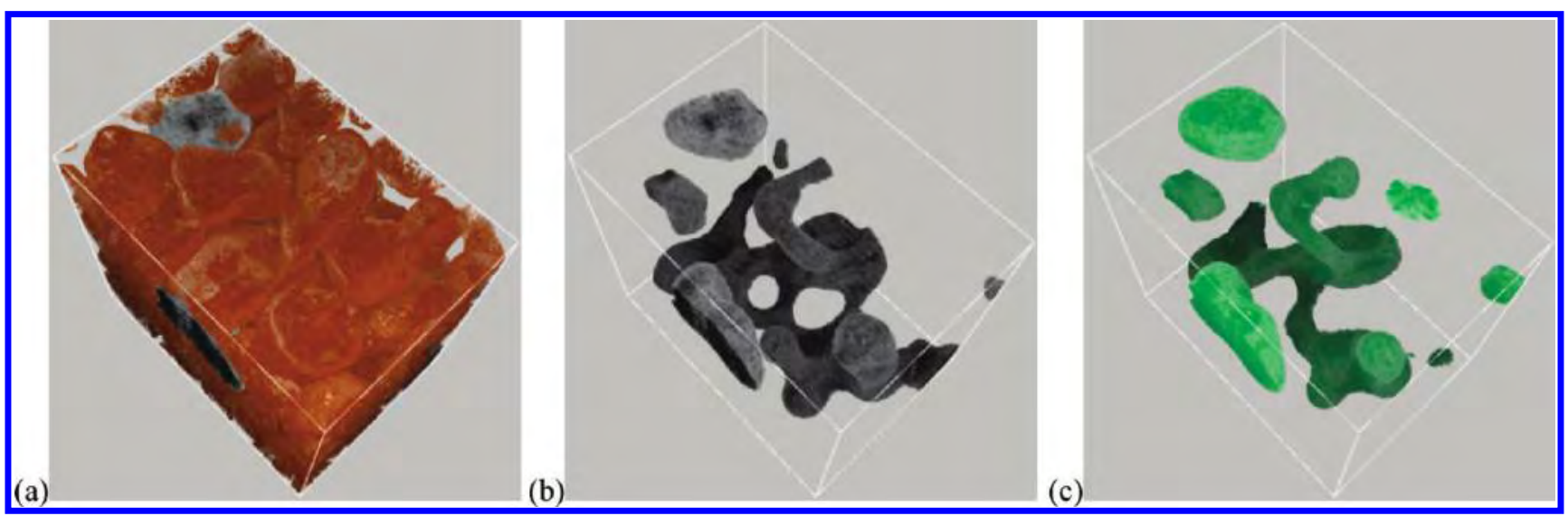

Figure 7. Visualization of a subvolume $(1.7 \mathrm{~mm} \times 1.4 \mathrm{~mm} \times 2.0 \mathrm{~mm})$ of the registered tomograms of spk H-H-L after (a, b) high-salinity secondary recovery, showing residual oil (black) and grains (brown, only in (a)) without salt solution, and after (c) low salinity tertiary recovery, showing only oil (green).

variations. Angles in the tomograms appear to be generally below $90^{\circ}$, but cannot be reliably quantified owing to resolution and segmentation limits. Instead, the angles are separately measured on model substrates under well-defined conditions in the following subsection.

The pore-scale residual distributions were obtained by summing the oil-segmented voxels within each pore to obtain its volume per pore volume and thus the pore's oil saturation. ${ }^{22,33}$ The oil occupancy statistics are presented in Figures 8-10.
The first, least discerning measure is the volume-weighted histogram of residual oil in Figure 8 . The plotted range of pore volumes corresponds to equivalent sphere radii from 62 to $620 \mu \mathrm{m}$. (This radius definition is to be distinguished from that in Figure $2 \mathrm{a}$, which refers to the radius of the largest inscribed sphere, and is lower by a factor of $1.7-2$ ) The subrange significantly contributing to residual oil volume in Figure 8 equates to pore radii from $\sim 110$ to $330 \mu \mathrm{m}$. The distributions for all flooded samples appear similar, with median pore radius within $220-240 \mu \mathrm{m}$. 


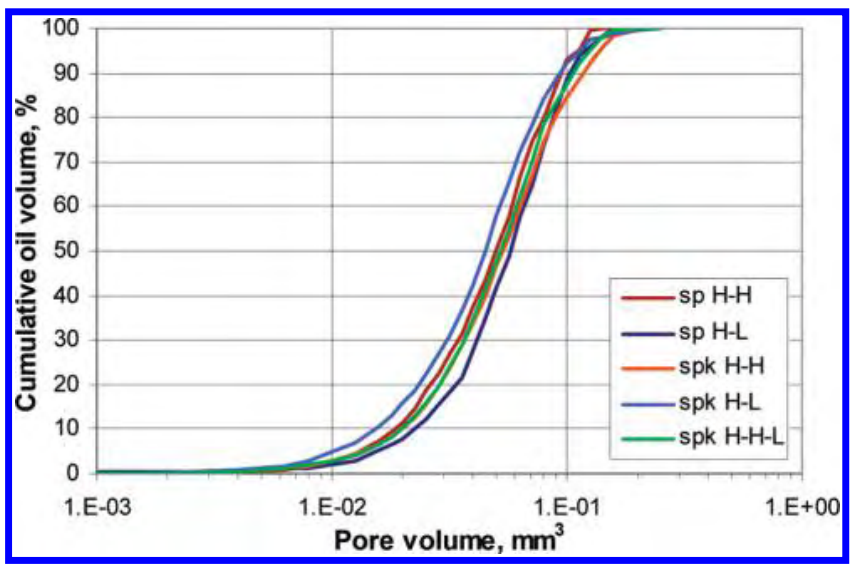

Figure 8. Normalized cumulative distribution of total volume of residual oil versus volume of pores in which it is trapped, from the segmented tomograms of the five flooded samples.

Among the slight differences, the residual for $s p H-H$ is in smaller pores than $s p H-L$, and that for $s p k H-H$ is in larger pores than spk $H$-L.

Figure 9 summarizes the pore occupancies versus their volume, now over the radius range $13-620 \mu \mathrm{m}$, and in the more sensitive form of number-weighted statistics. As most pores are completely water saturated, the scatter plots in Figure 9a-e include only those containing at least $1 \%$ oil. Moving averages of oil saturation are given over all pores (brown curve) and the subset with at least $50 \%$ oil occupancy (blue). The numberweighted histograms of all pores are given by the unfilled pink symbols.

Prior to interpreting Figure 9, it serves to further quantify the residual oil in terms of its connectivity. Oil in each pore was checked for connections to oil in neighboring pores to identify the continuous blobs and characterize their size via the number of pores each links. ${ }^{22,33}$ The histograms of blob size, weighted by the volume of oil in each, are given in Figure 10 for the five flooded packs. As in Figure 9, a lower cutoff for oil occupancy must be imposed. The dependence of the distributions on this definition is shown in Figure 10a for spk $H$-L. The 50\% cutoff was chosen here as the fairest compromise between over- or underestimation. The resulting distributions are shown in Figure 10b; alternative cutoff choices change the sizes but not the hierarchy between samples (as also seen in other studies ${ }^{22}$ ). While the relative volume of oil trapped as singlets or doublets is greatest for the kaolinite-free packs having lowest overall residual (Figure 4), the population of larger blobs is more dependent on the flood salinity. High salinity leaves more connected oil, with over half of the total residual volume comprising one very large cluster. The median blob size in Figure $10 \mathrm{~b}$ increases with $S_{\text {or }}$ in Figure 4 within the subsets of two and three samples last flooded at high or low salinity, respectively; however, there is no universal relation.

The trends in Figures 5-7 discussed above are consistent with these distributions. For spk $H-H$, the $64 \%$ of its residual oil left connected as one multicluster occupying 1110 pores provides a ready target for the tertiary recovery (spk $\mathrm{H}-\mathrm{H}-\mathrm{L}$ ) in Figures 6 and 7. This lowers its residual fraction and blob size to levels comparable to spk $H$ - $L$ directly flooded with low salinity. Indeed, the corresponding curves without the normalization by total residual volume in Figure 10b are almost overlain for all three low-salinity flooded samples (see Supporting Information).
A $\mu$-CT study of residuals after flooding of Fontainebleau sandstone and carbonates ${ }^{22}$ generally gave blob sizes of order of magnitude similar to the current study, while water-wet Berea sandstone ${ }^{21}$ showed mostly singlets and with the largest blob size

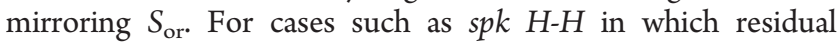
features span a substantial fraction of the tomogram dimensions, the imaged volume cannot be regarded as truly representative, and thus the trends (e.g., to large clusters for spk $\mathrm{H}-\mathrm{H}$ ) and their causes, rather than the absolute values, are the focus of this study.

We now return to Figure 9 and consider first the leftmost part of the plots, covering pore volumes of $10^{-5}-10^{-4} \mathrm{~mm}^{3}$, corresponding to intergrain smaller pores and deeper depressions in irregular grains. Despite their insubstantial contribution to the overall volumes (Figure 8 ), these pores are frequent; indeed even smaller pores arise in the segmented tomograms, but are difficult to differentiate from image noise and are not considered. The small pores in Figure 9 are most often waterfilled, by retention of the initial solution and/or oil displacement on flooding, and for three samples, the frequency of oil occupation is insignificant, as shown by the all-pores average curve (brown). For $s p H-L$, and to a lesser degree spk $H-H-L$, oil occupation is more common and displays a range of saturations. Their moving average for $>50 \%$ occupation (blue curve) in Figure $9 \mathrm{~b}$ and $\mathrm{e}$ is misleadingly lower than the other three samples, as the few occupied small pores of the latter tend to have high saturations. These two samples sp $H-L$ and spk $H-H-L$ also have the most finely divided blobs in Figure 10b, suggesting that oil trapping by snap-off is prevalent. Further, in the course of oil break-up and displacement from the large clusters of $s p k H-H$ in Figure $10 \mathrm{~b}$ by tertiary recovery $(s p k H-H-L)$, the oil occupation of small pores somewhat increases.

For larger pore volumes around $10^{-3} \mathrm{~mm}^{3}$, the continued lack of contribution to oil volume (Figure 8 ) is due both to the paucity of pores of this size in Figure 9 (shown by the low slope of the cumulative frequency distributions in pink) and the incomplete saturation of those which are occupied. Thus the $>50 \%$ moving averages decline, although the statistics there are poorest (especially for $s p H-H$ with least residual). Again $s p H-L$ has most number of occupied pores, although generally less than $10 \%$ saturated. As there is virtually no evidence of its pores bearing oil linings, these low saturations are mainly due to very small singlets (some of which are seen in Figure 5) and to the pore partition including small contributions from neighboring blob terminations.

For pore volumes increasing further to $10^{-2}-10^{-1} \mathrm{~mm}^{3}$, the strong contribution to oil volume in Figure 8 reflects the larger capacity, the coinciding onset of a significant frequency of occupied pores, and their increased oil saturation (i.e., the upturn of the all-pores moving averages). For $s p H-H$, the occupied pores are generally at least half full of oil, while for $s p H-L$, the broader range of low-intermediate saturations is again thought to be due to its frequent blob terminations partly intruding into neighboring pores. The density of scatter points is naturally greater for the high-residual kaolinite-coated samples. Their saturations shift downward and to a more uniform, random distribution in the sequence from spk $H-H$ to $s p k H-L$ to $s p k H-H-L$ in Figure $9 c-e$, again mirroring the corresponding blob size decrease in Figure 10b. The slight differences in the five allpores average curves follow the same hierarchy as their residuals in Figure 4. Compared to other $\mu$-CT studies, the scatter plots and all-pore averages are qualitatively similar to those from Fontainebleau sandstone flooding, ${ }^{22}$ while a broader spread of 


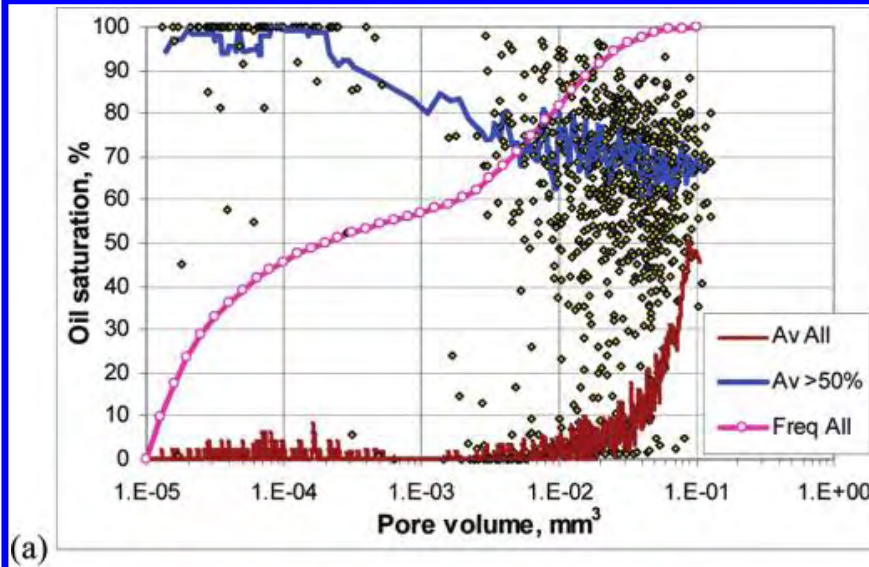

(b)
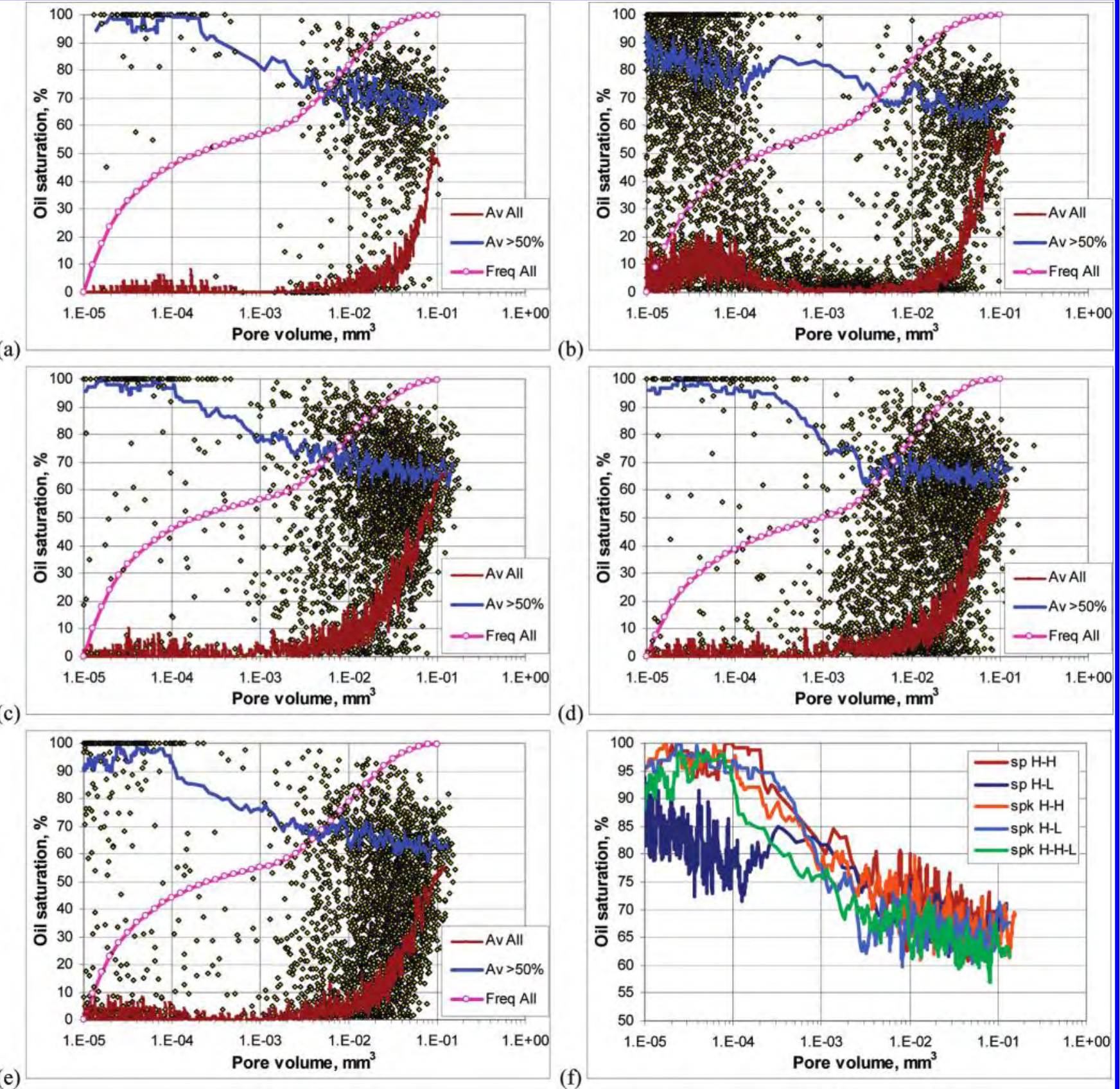

(d)

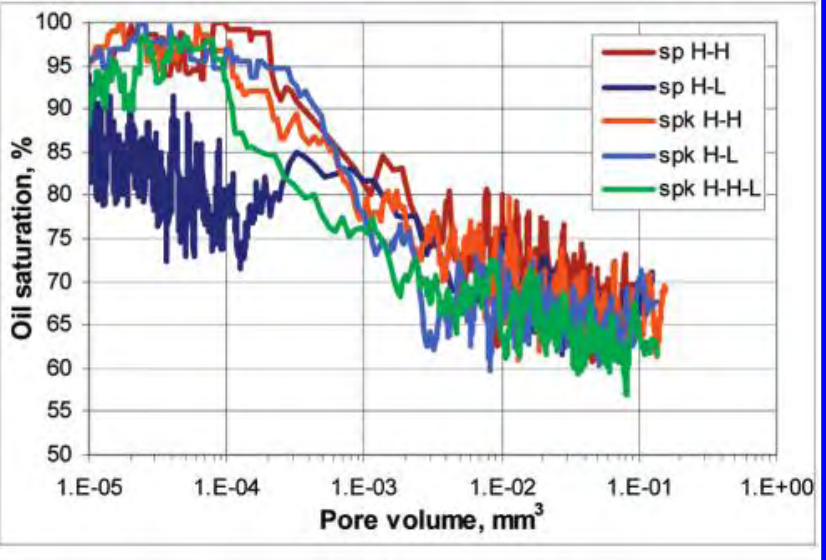

Figure 9. Scatter plots of oil saturation in each pore having $>1 \%$ oil occupancy versus its pore volume, from the segmented tomograms of the flooded samples: (a) sp H-H, (b) sp H-L, (c) spk H-H, (d) spk H-L, (e) spk H-H-L. Moving averages are in brown (all pores) and blue (>50\% occupied); the curves for $>50 \%$ occupation are compared in (f). The pink curves in (a)-(e) are cumulative frequency distributions of all pores, normalized to $100 \%$.

saturations across all pore sizes was inferred from water-wet Berea flooding. ${ }^{21}$

Molecular-Scale Mechanisms. The $\mu$-CT analysis characterizes the differences in pore-scale oil distributions, but cannot resolve kaolinite particles and wettability-altering asphaltenic deposits to pinpoint the molecular-scale causes. The supplementary suite of surface analytical techniques probes the interactions among oil, salt solution, and mineral which dictate the underlying wettability. The simplified systems replace grains by a glass slide and kaolinite-coated grains by kaolinite-coated glass, to facilitate quantification of contact angles and asphaltenic deposits. The analyses for the two solutions, $0.75 \mathrm{M} \mathrm{CsI} / \mathrm{NaCl}$ and $0.075 \mathrm{M} \mathrm{CsI}$, are compared to those using 0.75 and $0.075 \mathrm{M} \mathrm{NaCl}$, to assess the influence of the $\mu$-CT contrast agent on the observed recovery.

The receding and advancing contact angles of growing and retracting crude oil drops on these two model substrates in each of the four solutions are plotted in Figure 11. Judging from the advancing angles, glass is altered from water-wet to intermediatewet or moderately oil-wet after the $30 \mathrm{~min}$ in contact. The two $0.075 \mathrm{M}$ solutions behave similarly, while surprisingly, the $0.75 \mathrm{M}$ counterparts diverge somewhat. For $\mathrm{NaCl}$, both angles decrease with salinity, as often observed in such systems, ${ }^{10,13}$ while both increase for $\mathrm{CsI} / \mathrm{NaCl}$. As the receding angle tends to mirror the advancing trends, the alteration begins on first contact. 


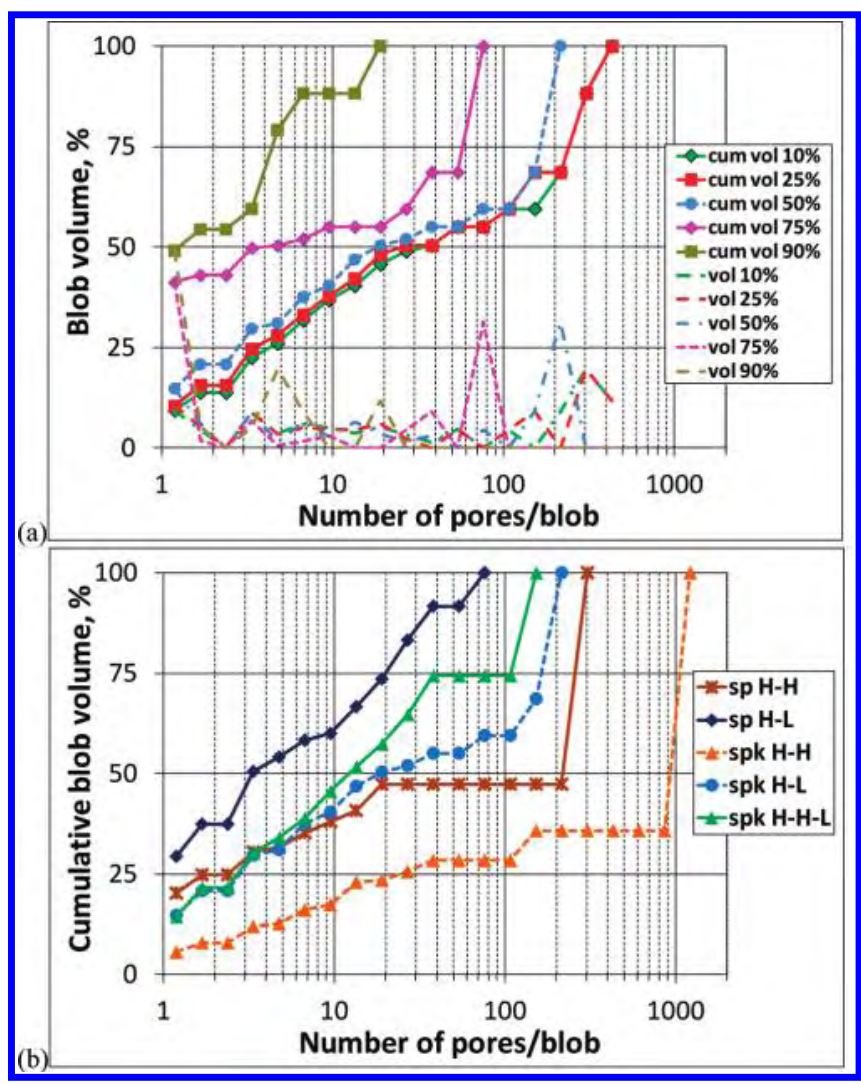

Figure 10. (a) Normalized incremental and cumulative volume distributions of residual oil blobs in spk $H-L$ versus blob size, defined as the number of pores each links, using the occupancy criteria of the blob filling $>10,25,50,75$, or $90 \%$ of a given pore's volume. (b) Cumulative volume distribution of blobs for all flooded samples, using the $50 \%$ occupancy cutoff.

In contrast, on kaolinite-coated glass the receding angles in all solutions are very similar, and the advancing angles are only slightly greater. The oil has a very limited ability to displace water surrounding kaolinite particles and instill adhesion during the $30 \mathrm{~min}$. While kaolinite remains largely water-wet, the advancing angle increases slightly with $\mathrm{NaCl}$ salinity, and decreases with $\mathrm{CsI} / \mathrm{NaCl}$, i.e., the opposite of the trends on glass.

The wettability alteration of the model substrates after drainage of each of the solutions by crude oil and aging was assessed by the extent of asphaltenic deposition. This procedure is not identical to that for the sand packs, in which the initial solution was $0.75 \mathrm{M} \mathrm{CsI} / \mathrm{NaCl}$ and salinity of the flood was varied, however it provides insight into the salt dependence of longerterm adhesion. Figure 12 shows representative FESEM images of the deposits for $0.75 \mathrm{M} \mathrm{CsI} / \mathrm{NaCl}$, qualitatively similar to those for the other solutions (see Supporting Information). On glass the deposits are a scattering of nanoparticle aggregates separated by relatively clean subareas. The area coverage of glass by deposit was quantified by image analysis, ${ }^{28}$ giving the coverage statistics in Table 1 from all micrographs. Whereas the values are quite low compared to some other oils, ${ }^{28}$ they are strongly correlated $\left(R^{2}=\right.$ $0.95)$ to the advancing angles on glass in Figure 11, suggesting that wettability alteration is established early and proceeds little (or similarly for all samples) thereafter.

For kaolinite-coated glass, the platelets remain almost completely free from nanoscopic deposits; the occasional larger

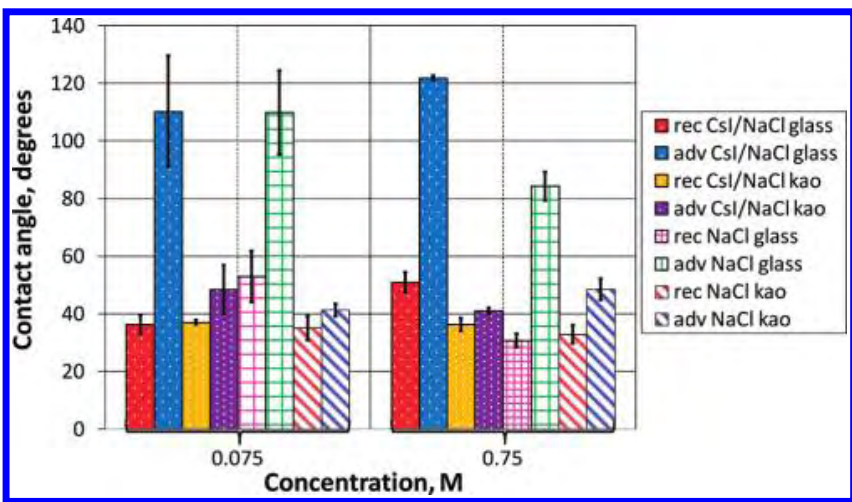

Figure 11. Average and standard deviation (error bar) of receding ( rec) and advancing ( $a d v)$ angles of crude oil drops (3 replicates) on glass and kaolinite-coated glass $(\mathrm{kao})$ in the $\mathrm{CsI} / \mathrm{NaCl}$ or pure $\mathrm{NaCl}$ solutions at the two concentrations.

agglomerate is due to sedimentation of asphaltene flocs preexisting in Tensleep oil. ${ }^{14}$ The amount of asphaltenic deposit was determined by extraction in chloroform/methanol for spectroscopic analysis of their natural fluorescence, yielding the inferred deposit mass per planar area of kaolinite-coated slide in Table 1. As expected, these values are all extremely low (compared to around $20 \mathrm{mg} / \mathrm{m}^{2}$ typical for other oils ${ }^{26}$ ), despite the extraneous contribution from the pre-existing flocs. Thus the water-wetness of kaolinite in Figure 11 is maintained throughout the longer aging.

These observations are consistent with those of the kaolinitecoated grains after flooding and disassembly of the pack to remove bulk oil. Representative FESEM images for $s p k H-L$ are shown in Figure 13; spk $H-H$ is qualitatively comparable. Open grain surfaces bear an incompletely covering texture of nanoscopic aggregated asphaltenics, similar to glass (Figure 12a), plus occasional submicrometer oil droplets (at the right in Figure 13b). Kaolinite remains relatively deposit-free, as for the model coats (Figure 12b). The asphaltenic mass extracted from the kaolinitecoated grains and assayed spectroscopically as above is listed in Table 1 . Both values are expectedly low, with $s p k H-H$ being the slightly smaller.

It appears that the differing residuals and pore-scale distributions in the sand packs mainly reflect their differing wettability. This is borne out by the negative correlation in Figure 14 between $S_{\text {or }}$ in Figure 4 for the sand without or with kaolinite and advancing angle in Figure 11 on glass or kaolinite-coated glass, respectively. As the mixed-wet samples are at most only moderately oil-wet in their altered subareas, further weakening of this oil-wetness and adhesion would be expected to reduce recovery by favoring oil disconnection during flooding. $8,9,16,17$ On glass, the higher contact angles in Figure 11 and slightly greater deposition in Table 1 for $0.75 \mathrm{M} \mathrm{CsI} / \mathrm{NaCl}$ thus tally with the greater recovery from uncoated sand by high salinity flooding (sp $H-H)$. The finely divided blobs in Figure $10 \mathrm{~b}$ for $s p H-L$ evidence the increased snap-off to which the increased waterwetness contributes. The $S_{\text {or }}$ for $s p H-L$ in Figure 4 is similar to the values of $\sim 15 \%$ typical for capillarity-driven recovery from homogeneous, water-wet bead packs. ${ }^{1,3}$ It is possible that the water-wet shift for $s p H-L$ is compounded by the osmotic pressure acting to dilute and thicken the high-salinity connate film intermingled between the sparse asphaltenic deposits which anchor oil to grains. As the concentration trends in Figure 11 and Table 1 are reversed if $\mathrm{CsI} / \mathrm{NaCl}$ is switched to $\mathrm{NaCl}$, low-salinity 


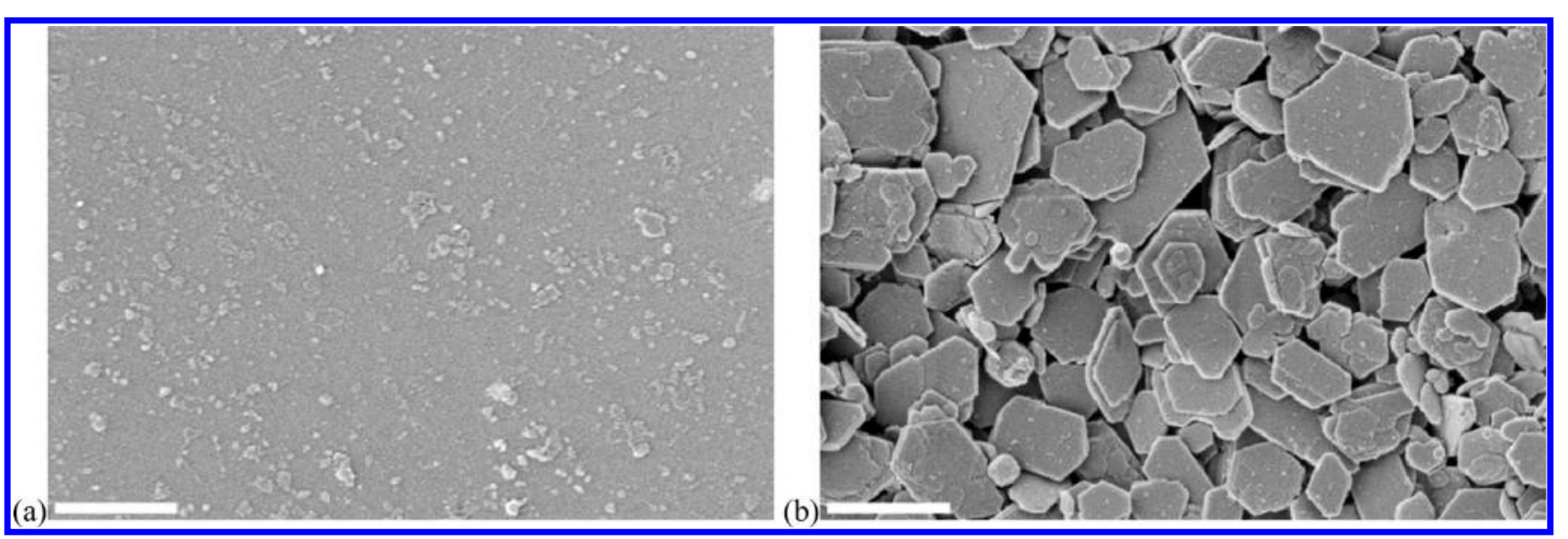

Figure 12. FESEM images of asphaltenic deposits on (a) glass and (b) kaolinite-coated glass after drainage of $0.75 \mathrm{M} \mathrm{CsI/NaCl} \mathrm{solution} \mathrm{by} \mathrm{oil} \mathrm{and}$ aging, followed by decalin-methanol rinsing. Scale bars are $0.5 \mu \mathrm{m}$.

Table 1. Average and Standard Deviation of Measured Surface Properties of Oil and Mineral Phases in the Four Salt Solutions of Given CsI and $\mathrm{NaCl}$ Concentrations

$\begin{array}{lcccccccc}{[\mathrm{CsI}], \mathrm{M}} & {[\mathrm{NaCl}], \mathrm{M}} & \xi \text { oil, } \mathrm{mV} & \xi \text { quartz, } \mathrm{mV} & \xi \text { kaolinite, } \mathrm{mV} & \begin{array}{c}\text { emulsion oil } \\ \text { drops, no. }{ }^{a}\end{array} & \begin{array}{c}\text { glass deposit, } \\ \text { coverage \% }{ }^{b}\end{array} & \begin{array}{c}\text { kaolinite deposit, } \\ \mathrm{mg} / \mathrm{m}^{2}{ }^{2}\end{array} & \begin{array}{c}\text { spk deposit, } \\ \mathrm{mg} / \mathrm{g}^{d}\end{array} \\ 0.125 & 0.625 & -15.8 \pm 2.5 & -11.1 \pm 1.7 & 4.2 \pm 0.6 & 79 \pm 3 & 6.38 \pm 0.85 & 0.70 & 0.027 \\ 0.075 & 0 & -27.3 \pm 1.4 & -29.1 \pm 1.6 & 7.8 \pm 0.4 & 133 \pm 14 & 6.20 \pm 1.08 & 1.17 & 0.030 \\ 0 & 0.75 & -4.2 \pm 1.1 & -14.7 \pm 0.9 & -6.4 \pm 0.7 & 74 \pm 12 & 4.65 \pm 0.67 & 1.21 & \\ 0 & 0.075 & -1.2 \pm 2.5 & -36.6 \pm 0.6 & -15.1 \pm 0.5 & 64 \pm 36 & 5.88 \pm 1.44 & 1.17\end{array}$

${ }^{a}$ Number of oil drops stabilized by kaolinite. ${ }^{b}$ Area coverage of glass slides by asphaltenic deposit after aging. ${ }^{c}$ Mass (mg) of asphaltenic deposit on kaolinite-coated glass per slide area $\left(\mathrm{m}^{2}\right)$ after aging. ${ }^{d}$ Mass $(\mathrm{mg})$ of asphaltenic deposit remaining on kaolinite-coated sand per sand mass $(\mathrm{g})$ after flooding by the CsI/ $\mathrm{NaCl}$ solutions.

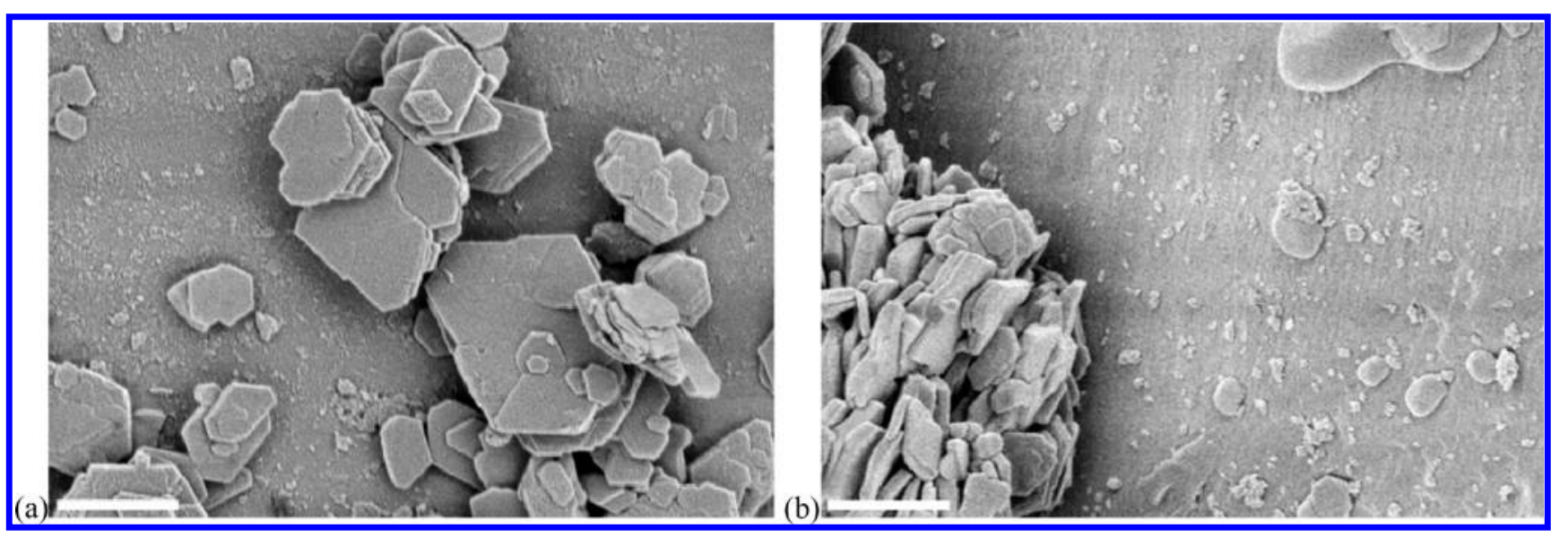

Figure 13. FESEM close-ups of kaolinite-coated sand from spk $H$ - L after drainage, aging, and flooding with $0.075 \mathrm{M}$ CsI solution, followed by methanol rinsing. Scale bars are $0.5 \mu \mathrm{m}$.

flooding may give more complete recovery than high-salinity for the $\mathrm{NaCl}$ solutions of greater relevance to real reservoir brines.

The partial coverage of grains by kaolinite particles which retain surface water strongly increases residual oil. An effective contact angle can be estimated for kaolinite-coated grains via Cassie's law: ${ }^{34}$

$$
\cos \theta_{c}=f_{1} \cos \theta_{1}+f_{2} \cos \theta_{2}
$$

Here $\theta_{c}$ is the contact angle on the composite surface comprising materials $i=1$ and 2 of area fraction $f_{i}$ within which the corresponding angles are $\theta_{i}$. From analysis of 60 FESEM images, each $60 \mu \mathrm{m} \times 40 \mu \mathrm{m}$, of untreated coated grains (see Supporting Information), the projected area fraction covered by kaolinite averages $26 \%$ with standard deviation $16 \%$. The composite advancing angle from eq 1 for this fraction and the advancing values on glass and kaolinite-coated glass in Figure 11 is indicated by the two points marked by crosses in Figure 14. The correlation for the composite is poorer than for kaolinite alone, suggesting that kaolinite plays a greater role than merely contributing to wettability via eq 1 . This is further evidenced by the fact that the $S_{\text {or }}$ in Figure 4 


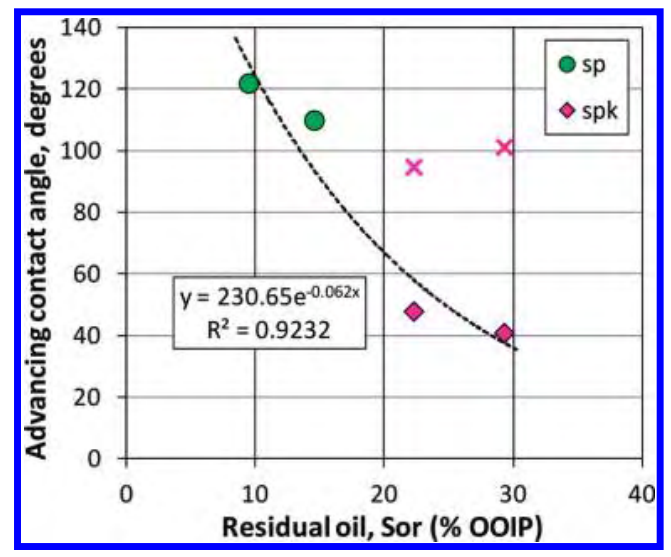

Figure 14. Correlation between residual oil in the sand packs without $(s p)$ or with $(s p k)$ kaolinite after flooding and the advancing angle of a crude oil drop on glass without or with kaolinite coating, respectively, in the corresponding flooding solution. Crosses indicate the contact angles predicted by eq 1 for kaolinite-coated sand.

for all three coated packs significantly exceed the $\sim 15 \%$ expected in the strongly water-wet extreme. ${ }^{1,3}$

One possible explanation for the largest residual and cluster size in Figure $10 \mathrm{~b}$ for $s p k \mathrm{H}-\mathrm{H}$ is that the grains are sufficiently water-wet, and thickly sheathed by water films in the roughness and pores of the kaolinite lining, that the pack becomes prone to oil bypassing due to rapid spontaneous imbibition of water along pathways preferred or established by capillarity. Despite the relatively homogeneous packing, domains of somewhat larger, connected pores exist and often coincide with the location of residual oil (Figures 6 and 9). Bypassing in homogeneous pore networks has also been seen in $2 \mathrm{D}$ glass micromodels ${ }^{1}$ of uniform pore and throat sizes with intermediate aspect ratio (around 3) similar to our packs (Figure 2b). On kaolinite, the slightly higher advancing angle in Figure 11 and slightly greater deposition (also on the lined grains) in Table 1 for $0.075 \mathrm{M}$ CsI are in line with spk $H-L$ becoming less water-wet during low-salinity flooding to reduce bypassing and increase recovery. The primary trapping mechanism switches to snap-off, evidenced by the decrease in blob size for spk $H-L$ and spk $H-H-L$.

It is again conceivable that osmotic pressure aids the drawing in of low-salinity solution between oil and grain, especially given the increased access afforded by the kaolinite, to displace or trap oil, depending on the aspect ratio. Further, some degree of kaolinite mobilization may occur. As one check for migration, the effluent from spk $H-H$ and spk $H-L$ was centrifuged at $1000 \mathrm{~g}$ for $10 \mathrm{~min}$. No kaolinite sediment was visually apparent; however, this test cannot detect traces in such small volumes, and mobilized particles may be recaptured by downstream grains or the frit. It is possible that for spk $H-L$ and spk $H-H-L$, the expected increase in electrostatic repulsions at low salinity leads to partial removal of kaolinite and rapid alteration of exposed grain patches toward oilwetness to aid recovery. The emulsion test in Table 1 shows that mobilized kaolinite can interfacially stabilize crude oil drops in all salt solutions, and more so in $0.075 \mathrm{M}$ CsI. This may further aid recovery by reducing snap-off, or disadvantage recovery by hindering snapped-off blobs from recoalescing. ${ }^{2 f}$

Zeta potential of oil, quartz, and kaolinite in the solutions can give insight into the electrostatic interactions contributing to the observed wettability and in turn oil recovery. The measured potentials, all at natural $\mathrm{pH}$ around 6 , are listed in Table 1. In the
$\mathrm{NaCl}$ solutions, the oil is close to its isoelectric point and thus a significant fraction of its surface base groups are protonated and attracted to the deprotonated acid sites on quartz. This is consistent with the glass wettability alteration in Figure 11, which reduces at high $\mathrm{NaCl}$ in line with the weakened attraction. However, as Tensleep crude has relatively low acid and base numbers, and many of these groups are internalized in preexisting asphaltene aggregates, the coarse but sparse deposition on glass is presumably driven not only by electrostatic and van der Waals attractions but also by surface precipitation and hydrophobic attractions. Kaolinite is less negatively charged than quartz in Table 1, partly contributing to its water-wetness, although the above-mentioned capillary retention of thicker water films is presumably the main cause. Compared to the $\mathrm{NaCl}$ solutions, zeta potentials in their $\mathrm{CsI} / \mathrm{NaCl}$ analogs in Table 1 are slightly less negative for quartz, but much more negative for oil, and reverse to positive for kaolinite. Unlike $\mathrm{NaCl}$, CsI is potential determining, with $\mathrm{I}^{-}$ions binding to the oil interface and $\mathrm{Cs}^{+}$to kaolinite. The fact that angles and deposits are relatively unchanged by this drastic switch again points to the importance of nonelectrostatic interactions for the preaggregated oil. Further, these oppositely charged monovalent ions on oil and kaolinite give little or no extra scope for interfacial bonding to develop adhesion.

\section{- CONCLUSIONS}

This study demonstrated the integration of $\mu$-CT imaging with supplementary surface analyses to visualize and quantify both the distribution of residual oil blobs in pores after waterflooding and the finer features such as nanoscale oil deposits on pore walls, to thus trace the effect of recovery to its cause. The approach is expected to be broadly applicable to reservoir rocks having pores resolvable by $\mu$-CT, since FESEM imaging of deposits can be performed on cut rock faces, and the parallel analyses of dressed model substrates can be further extended to other relevant minerals. For the quartz sand packs addressed here, the presence of a gravimetrically minute fraction of kaolinite had a substantial effect on oil recovery, owing to its distribution as a patchy lining of considerable grain coverage. The kaolinite was found to diminish oil recovery and reverse its dependence on waterflood salinity, in line with the wettability trends. These results are naturally tied to the choice of crude oil and salt solutions. Many other oils display a high affinity for kaolinite, ${ }^{24-26}$ in which case the platelets can increase, rather than reduce, overall oil-wetness. Moreover, such affinities are dependent on the presence of divalent cations, which were omitted from the study to simplify both the interpretation of interactions and analysis of the effect of the added X-ray contrasting salt. Although this CsI did not appear to substantially influence the results as compared to $\mathrm{NaCl}$, the impact of its binding to oil and mineral surfaces must be evaluated in such $\mu$-CT studies.

\section{ASSOCIATED CONTENT}

S Supporting Information. Fluorescence spectra used to determine asphaltenic deposit amounts (Figure S1), scatter plots of oil saturation from $\mu$-CT (Figure S2), cumulative volume distributions of oil blobs from $\mu$-CT (Figure S3), FESEM images of asphaltenic deposits on model substrates (Figures S4-S5), and FESEM images of kaolinite-coated grains (Figure S6). 
This information is available free of charge via the Internet at http://pubs.acs.org/.

\section{AUTHOR INFORMATION}

\section{Corresponding Author}

*Telephone: +61-261254823. Fax: +61-261250732. E-mail: andrew.fogden@anu.edu.au.

\section{ACKNOWLEDGMENT}

Financial support from the member companies of the Digital Core Consortium Wettability Satellite and an ARC Discovery Grant (A.F.) are acknowledged. Michael Turner, Jill Middleton, Adrian Sheppard, and Mark Knackstedt (ANU) are thanked for assistance with $\mu$-CT analysis. Warwick Hillier (RSB at ANU) is thanked for access to the FluoroMax instrument.

\section{REFERENCES}

(1) Chatzis, I.; Morrow, N. R.; Lim, H. T. SPE 1983, 23, 311-326.

(2) Lenormand, R.; Zarcone, C.; Sarr, A. L. Fluid Mech. 1983, 135, 337-353.

(3) Morrow, N. R.; Chatzis, I.; Taber, J. I. SPE Res. Eng 1988, 3, 927-934.

(4) Chatzis, I.; Morrow, N. R. SPE 1984, 24, 555-562.

(5) Chatzis, I.; Kuntamukkula, M. S.; Morrow, N. R. SPE Res. Eng 1988, 3, 902-912.

(6) Salathiel, R. A. Trans. Am. Inst. Min., Metall., Pet. Eng., Soc. Min. Eng. AIME 1973, 255, 1216-1224.

(7) Morrow, N. R. I. Pet. Technol. 1990, 42, 1476-1484.

(8) Jadhunandan, P. P.; Morrow, N. R. SPE Res. Eng 1995, 10, 40-46.

(9) Hamon, G. Proceedings of the SPE Annual Technical Conference, Dallas, Texas, Oct 1-4, 2000; Paper 63144.

(10) Buckley, J. S.; Morrow, N R. An overview of crude oil adhesion phenomena. In Physical Chemistry of Colloids and Interfaces in Oil Production; Toulhoat, H., Lecourtier, J., Eds.; Éditions Technip: Paris, 1992.

(11) Buckley, J. S.; Liu, Y.; Xie, X.; Morrow, N. R. SPE 1997, 2, $107-119$.

(12) Yang, S.-Y.; Hirasaki, G. J.; Basu, S.; Vaidya, R. L.Pet. Sci. Eng 1999, 24, 63-73.

(13) Liu, L.; Buckley, J. S. L. Pet. Sci. Eng 1999, 24, 75-83.

(14) Lord, D. L.; Buckley, J. S. Colloids Surf. A 2002, 206, 531-546.

(15) Kovscek, A. R.; Wong, H.; Radke, C. J. AIChE J. 1993, 39, 1072-1085.

(16) Dixit, A. B.; Buckley, J. S.; McDougall, S. R.; Sorbie, K. S. Transp. Porous Media 2000, 40, 27-54.

(17) Øren, P.-E.; Bakke, S. L. Pet. Sci. Eng. 2003, 39, 177-199.

(18) Sakellariou, A.; Sawkins, T. J.; Senden, T. J.; Limaye, A. Phvs. A 2003, 339, 152.

(19) Sheppard, A. P.; Sok, R. M.; Averdunk, H. Proceedings of the International Symposium of the Society of Core Analysts, Toronto, Canada, Aug 21-25, 2005; Paper 20.

(20) Latham S.; Varslot T.; Sheppard A. P. Proceedings of the International Symposium of the Society of Core Analysts, Abu Dhabi, UAE, Oct 29-Nov 2, 2008; Paper 35.

(21) Seright, R. S.; Prodanovic, M.; Lindquist, W. B. SPE 2006, 11, 159-170.

(22) Kumar, M.; Senden, T. J.; Sheppard, A. P.; Middleton, J. P.; Knackstedt, M. A. Petrophysics 2010, 51, 323-332.

(23) Kumar, M.; Fogden, A. Langmuir 2010, 26, 4036-4047.

(24) Durand, C.; Rosenberg, E. L. Pet. Sci. Eng. 1998, 19, 65-72.

(25) Lebedeva, E. V.; Fogden, A. Environ. Sci. Technol. 2010, 44, 9470-9475.

(26) Lebedeva, E. V.; Fogden, A. Colloids Surf., A 2011, 377, 115-122.

(27) Fogden, A.; Kumar, M.; Morrow, N. R.; Buckley, J. S. Energy Fuels 2011, 25, 1605-1616.
(28) Lebedeva, E. V.; Fogden, A. Colloids Surf. A 2011, 380, $280-291$.

(29) Chipera, S. J.; Bish, D. L. Clavs Clav Miner. 2001, 49, 398-409.

(30) Borden, D.; Giese, R. F. Clavs Clav Miner. 2001, 49, 444-445.

(31) Pruett, R. J.; Webb, H. L. Clavs Clav Miner. 1993, 41, 514-519.

(32) Bryant, S.; Johnson, A. I. Colloid Interface Sci. 2003, 263, 572.

(33) Singh, K.; Niven, R. K.; Senden, T. J.; Turner, M. L.; Sheppard, A. P.; Middleton, J. P.; Knackstedt, M. A. Environ. Sci. Technol. 2011, 45, 3473-3478.

(34) Cassie, A. B. D.; Baxter, S. Trans. Faradav Soc. 1944, 40, $546-551$. 